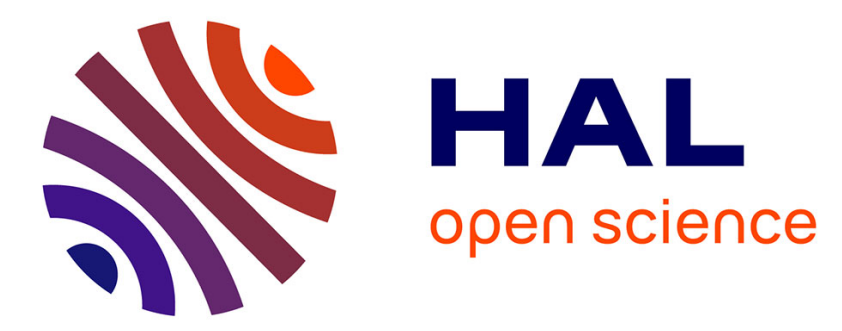

\title{
Geometrical optimization of SRM on operating mode for automotive application
}

\author{
M'Hamed Belhadi, Guillaume Krebs, Claude Marchand, Hala Hannoun, \\ Xavier Mininger
}

\section{- To cite this version:}

M'Hamed Belhadi, Guillaume Krebs, Claude Marchand, Hala Hannoun, Xavier Mininger. Geometrical optimization of SRM on operating mode for automotive application. Electrical Engineering, 2017, 10.1007/s00202-016-0504-0 . hal-01677601

\section{HAL Id: hal-01677601 https://hal.science/hal-01677601}

Submitted on 11 Mar 2020

HAL is a multi-disciplinary open access archive for the deposit and dissemination of scientific research documents, whether they are published or not. The documents may come from teaching and research institutions in France or abroad, or from public or private research centers.
L'archive ouverte pluridisciplinaire HAL, est destinée au dépôt et à la diffusion de documents scientifiques de niveau recherche, publiés ou non, émanant des établissements d'enseignement et de recherche français ou étrangers, des laboratoires publics ou privés. 


\title{
Geometrical optimization of SRM on operating mode for automotive
}

\section{application}

\author{
M’Hamed Belhadi $^{1,2}$, Guillaume Krebs ${ }^{1}$, Claude Marchand ${ }^{1}$, Hala Hannoun ${ }^{2}$ and Xavier Mininger ${ }^{1}$
}

${ }^{1}$ : GeePs, Group of electrical engineering of Paris, UMR CNRS 8507, CentraleSupélec, Univ. Paris-Sud, Université Paris-Saclay, Sorbonne Universités, UPMC Univ Paris 06

3 \& 11 rue Joliot-Curie, Plateau de Moulon 91192 Gif-sur-Yvette CEDEX, France

2: Renault, 1 avenue du Golf, 78288 Guyancourt, France

mhbelhadi@yahoo.fr, guillaume.krebs@geeps.centralesupelec.fr

Corresponding author name: M’Hamed Belhadi

Corresponding author e-mail: mhbelhadi@yahoo.fr.0033651435106 
Abstract - This paper deals with double saliency switched reluctance motor for automotive application by offering simultaneously a design solution to the drawbacks of torque ripples and emitted noise caused by the important radial efforts. The work concerns the optimization of the motor structure, the main objectives is the reduction of the first harmonics of torque and radial force applied on the stator teeth. This geometric optimization is performed on operating points where the instantaneous computation of supply current is taken into account to resolve simultaneously both problems. This operating point is defined as torque-speed point by considering the instantaneous characteristics of the machine when the steady state is established.

Index Terms — Switched reluctance motor, automotive application, torque ripple, radial effort, geometrical optimization.

\section{INTRODUCTION}

Thanks to its many advantages, the switched reluctance motor (SRM) is a serious candidate for the automotive application particularly in the electric vehicle (EV) traction. The SRM is well known for its simple geometry which simplifies maintenance and manufacturing (cost reduced), the lack of magnets and windings in the rotor which allows operating in harsh environment (high speed and high temperature), the concentrated winding that reduces copper losses... However, this motor presents two major drawbacks which are torque ripples [1] and the important radial efforts applied on the stator [2]. The first ones cause comfort degradation of EV users and the second ones are the main source of stator vibrations and emitted noise. As a consequence, solutions to these problems have to be given in order to use this machine for EV traction at large-scale. In the literature, mainly three approaches are considered: control approach [3]-[8], compensation approach [9]-[11] and the design modification approach [12]-[22]. In these approaches, the two problems are usually independently studied. This is not the case of the present work, in which both are studied simultaneously. Indeed, the design modification approach is focused by considering geometrical optimization to simultaneously limit both drawbacks. Furthermore, the instantaneous value of supply current with optimal control parameters is considered on the operating point (speed-torque).

\section{MACHINES PRESENTATION}

In order to optimize the SRM structure, a comparative study is performed with an existing one considered as a reference,

named original SRM "SRM powertrain. The objective is then the improvement of its performances i.e. the decrease of torque ripples and radial forces. 


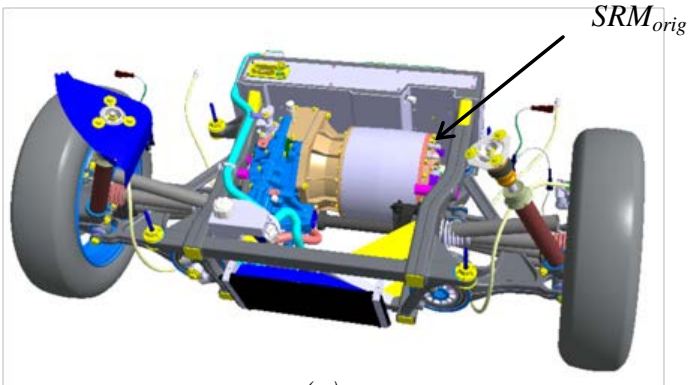

(a)

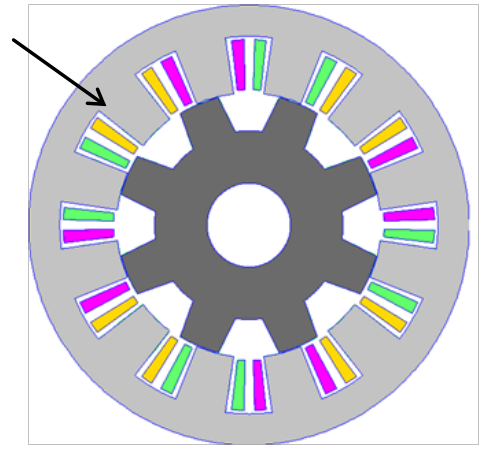

Fig. 1 SRM orig, (a) powertrain structure, (b) machine structure

For confidentiality reasons, the dimensions as well as the characteristics of motors are not given throughout all this work. Consequently, the values of the different variables, including rotor position, are normalized with respect to the $\mathrm{SRM}_{\text {orig }}$ ones.

\section{OPTIMIZATION PROCESS}

In this section, the description of optimization process, objective function, considered geometrical parameters and initial operating point are detailed.

\subsection{Description of the process}

The automotive application requires a wide range of operating points (torques-speeds). The average torque control method is used here. Then, for each operating point (OP), different control parameters (reference current $I_{r e f}$, conduction angle $\theta$, firing angle $\psi$, see fig. 2) must be chosen. The choice of these parameters is based on desired machine performances: maximum torque, minimal ripples ... Here, the instantaneous supply current is assumed slightly influenced by the geometrical modifications

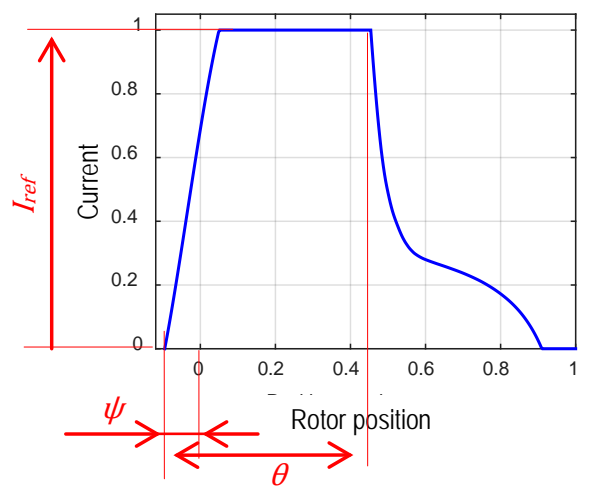

in order to exclusively perform a geometrical optimization, which reduces the computation time.

Fig. 2 Control parameters 
The geometrical optimization procedure, which uses a genetic algorithm, is initially made for one operating point to reduce the computation time. The obtained results are then verified for all the operating range. In this work, the Matlab optimisation toolbox has been used [23]. This toolbox offers many optimization algorithms among then, the genetic algorithm which allows finding the global optima. The objective is not only to reduce the radial forces and the torque ripples but also to keep an equivalent average torque ( $\mathrm{T}_{\text {avg }}$ ) as in the reference machine $S R M_{\text {orig. }}$. First harmonics of the radial force $h_{f 1}$ and of the torque $h_{c 1}$ are minimized here, as they have been identified by the industrial partner as critical harmonics which lead respectively to the noise emission and to degradation of the user's comfort. Figure 3 shows the influence of these harmonics on the instantaneous torque and radial force curves. It can be noticed that, by omitting $\mathrm{h}_{\mathrm{f} 1}$ and $\mathrm{h}_{\mathrm{c} 1}$, the radial force and torque ripples are considerably reduced.

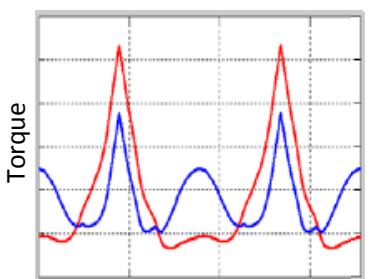

Rotor position

(a)

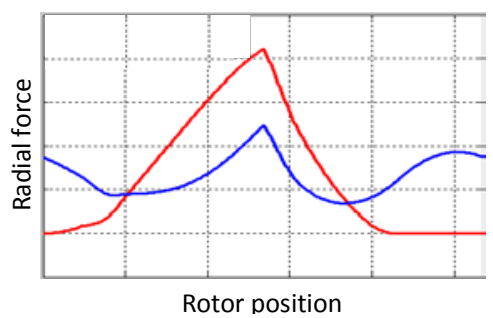

(b)

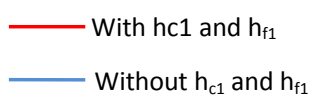

Fig. 3 Instantaneous torque and radial force with and without $h_{c 1}$ and $h_{f 1}$

Once the problem is defined, the optimization process can be implanted. Figure 4 presents the main steps of this process where the finite element (FE) simulation is combined with temporal simulation (instantaneous analytical computation). The different steps can be summarized as:

Step 1, definition of initial geometry: here the starting point of geometrical structure is defined. Seen that the target is an improvement of the original structure, this one is used as the initial geometry. The static characteristics will then be computed by finite element analysis with the help of Femm 4. 2 [24]. Those characteristics include torque, flux and radial force as a function of rotor position and supply current.

Step 2, choice of operating point (OP): as mentioned above, the optimization is first performed on one operating point i.e. for one speed and one torque. So, this operating point must be well chosen to limit the influence of control parameters on the geometrical optimization process. In this step, the speed $\Omega$ and the control parameters will be determined. 
Step 3, calculation of the instantaneous current: once the operating point is chosen, this step consists in the determination of the instantaneous current shape $i(t)$ from a temporal simulation. This current will be considered unchanged on the next step, where, it will be inserted on finite element analysis.

Step 4, research of optimal geometry: this is the most important step. Indeed, the optimization loop will be carried out by using the genetic algorithm in this step. Furthermore, finite element analyse is here chosen to find the optimal geometry for the

\section{reason described below.}

Step 5, validation of this optimized SRM: in this step, the performances of the optimized structure will be checked for all operating points. SRM can be then rejected or retained detailed study.

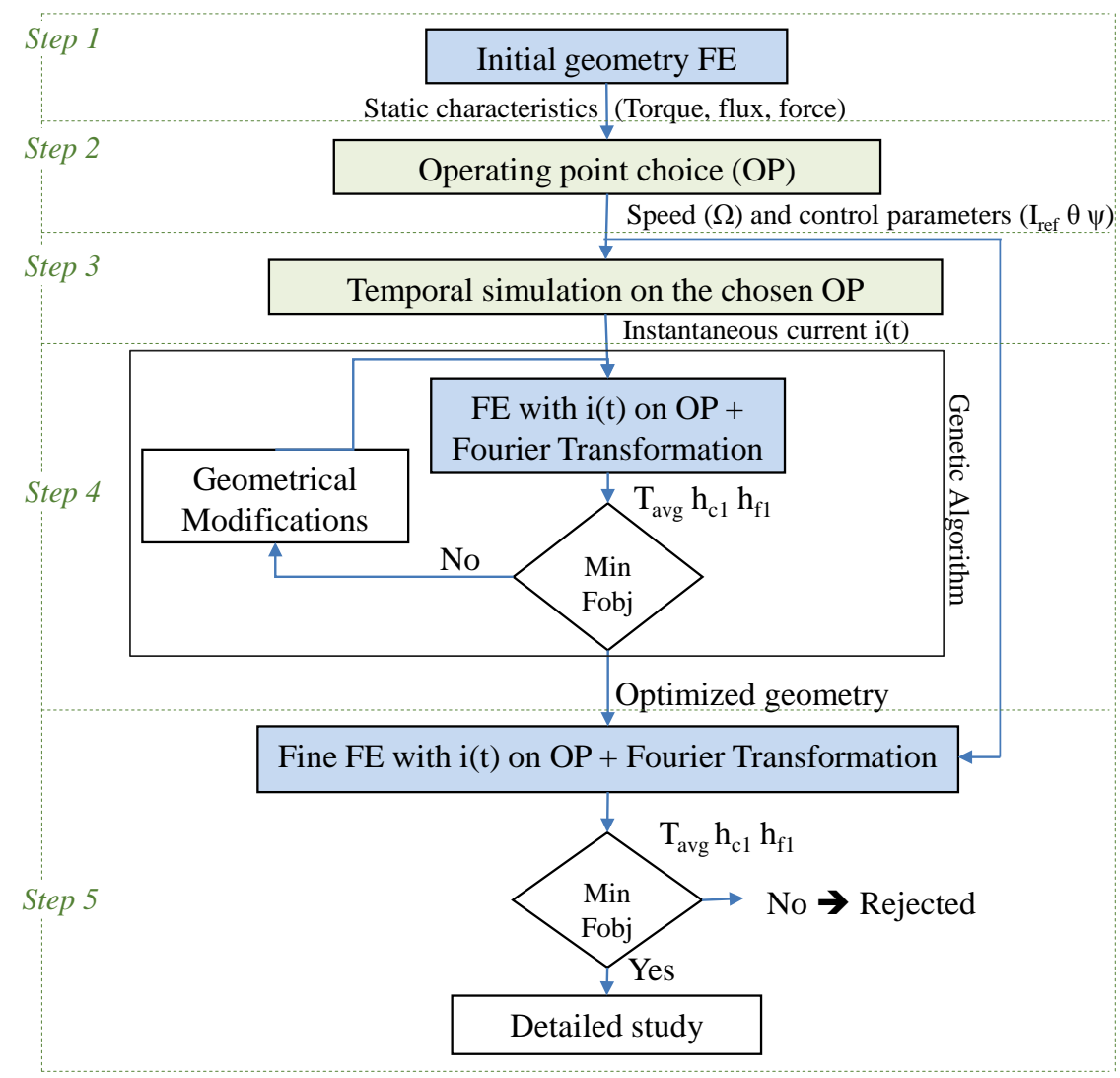

Fig. 4 . Optimization process

The complex flux distribution of SRM increases the complexity of magnetic analytical or/and semi-analytical model developments. It is why a magnetic 2D FE model has been here considered. Furthermore, this FE model allows an accurate study. In order to reduce the computation time, the mono-objective and unconstrained optimization is considered and parallel computation proposed by Matlab is used. 


\subsection{Objective function}

The objective function that has to be minimised, which considers torque and force values normalized with respect of $\mathrm{SRM}_{\text {orig }}$ values ( $T_{n o r}, h_{\text {fnor }}, h_{\text {cnor }}$ ), is given by equation (1). The objective of this function is to maximize the average torque and to reduce the fundamental harmonics of torques and radial forces.

$$
F_{o b j}=\left(\frac{T_{a v g}}{T_{\text {nor }}}\right)^{-1}+\frac{h_{c 1}}{h_{c n o r}}+\frac{h_{f 1}}{h_{\text {fnor }}}
$$

\subsection{Choice of geometrical parameters and operating point}

The stator and rotor poles arcs (respectively $\beta_{\mathrm{s}}, \beta_{\mathrm{r}}$ ) are among the most influencing geometrical parameters on torque ripples and radial forces[1] [12]. Moreover, this result has been confirmed in a detailed study that can be consulted in the reference [25]. Thus, those parameters are considered here (Fig. 5-a). In the considered optimization, low speeds are mainly focused. Indeed, at high speeds, the acoustic noise related to radial magnetic efforts are not dominating comparing to mechanical and aerodynamic contributions and the torque ripples are mechanically filtered. The considered operating point is then at the speed of 0.033×maximum speed (Fig. 5-b). Furthermore, the maximum torque at this speed is taken into account, which allows considering that the reference current $\left(\mathrm{I}_{\mathrm{ref}}\right)$ and conduction angle $(\theta)$ are considered at their maximal values $\left(I_{\text {ref }}=I_{\max }, \theta=180^{\circ}\right)$.

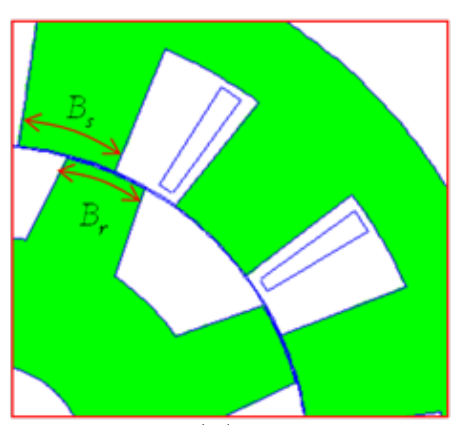

(a)

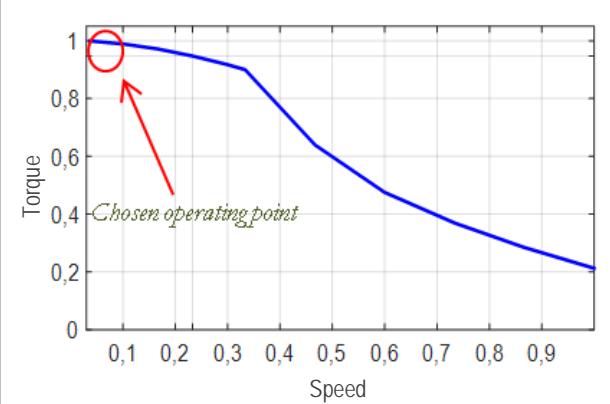

(b)

Fig. 5 geometrical parameters and considered operating point 


\section{RESULTS AND DISCUSSION}

\section{1. $\quad$ Optimized SRM}

The rotor pole arc of the optimized machine "SRM $\mathrm{Sptim}$ " is equal to $0.84 \beta_{\mathrm{r}_{\text {orig }}}$ and its stator pole arc to $0.94 \beta_{\mathrm{s}_{\_} \text {orig. }}$. These poles arcs of optimized SRM ( $\beta_{r_{-} \text {optim }}, \beta_{\text {s_optim}}$ ) are close each to other $(5 \%)$. The cross sections of flux are reduced in the rotor and the stator compared to the $\mathrm{SRM}_{\text {orig. }}$

\subsection{Instantaneous values}

Fig 6 presents the instantaneous torque and radial force as function of rotor position at the considered operating point.

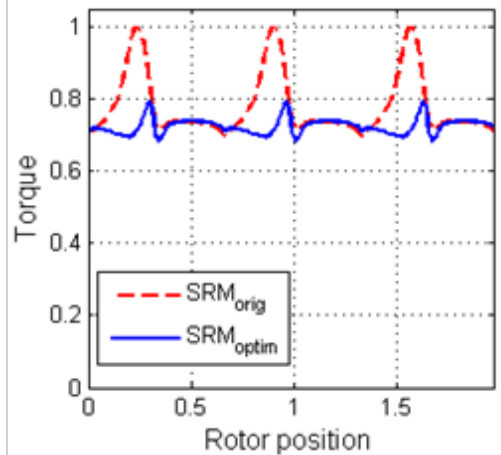

(a)

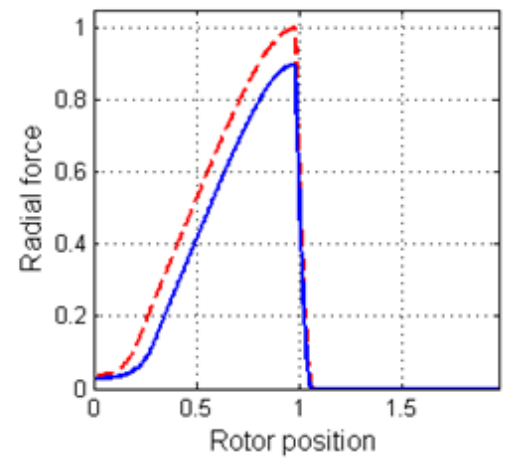

(b)

Fig. 6. Instantaneous values,(a) torque, (b) radial force

The optimization allows a simultaneously reduction of the torque ripples and radial force compared to the $\mathrm{SRM}_{\text {orig. }}$. Indeed,

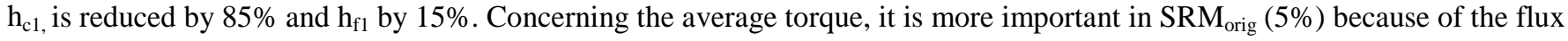
section reduction and the reduction of saliency ratio. Last has decreased the converted energy in $\mathrm{SRM}_{\mathrm{optim}}$. Furthermore, the original SRM has already been optimized to maximize the average torque in its design process. So, coefficients can be added on the objective function in order to improve the average toque in optimized SRM.

\subsection{Speed-torque curve}

In our application, one of the specifications is the compliance to a defined torque-speed curve. This curve is defined as a maximum average torque developed by the SRM, when it is supplied by the maximum current and maximum voltage. The 
optimization of the control parameters is taken into account. In our case, the average torque control method is considered. Those curves give the possibility to study several operating points and to consider the entire speed range.

In this work, the determination of speed-torque curves is carried out with a laboratory software named "MRVSIM" [26]. MRVSIM is a design and sizing code developed under MATLAB ${ }^{\circledR}$ environment for radial switched reluctance machines with double saliency. The software considers simultaneously the machine and its converter. By using analytical and/or numerical models and by taking into account the optimization of the control parameters, the software can determine the different characteristics of each operating point. FE computation is here used for an accurate determination of the different static characteristics like torque, flux and radial force as a function of the supply current and the rotor position.

The figure 7 shows the torque-speed curves, with the corresponding radial force and torque ripples as a function of speed.
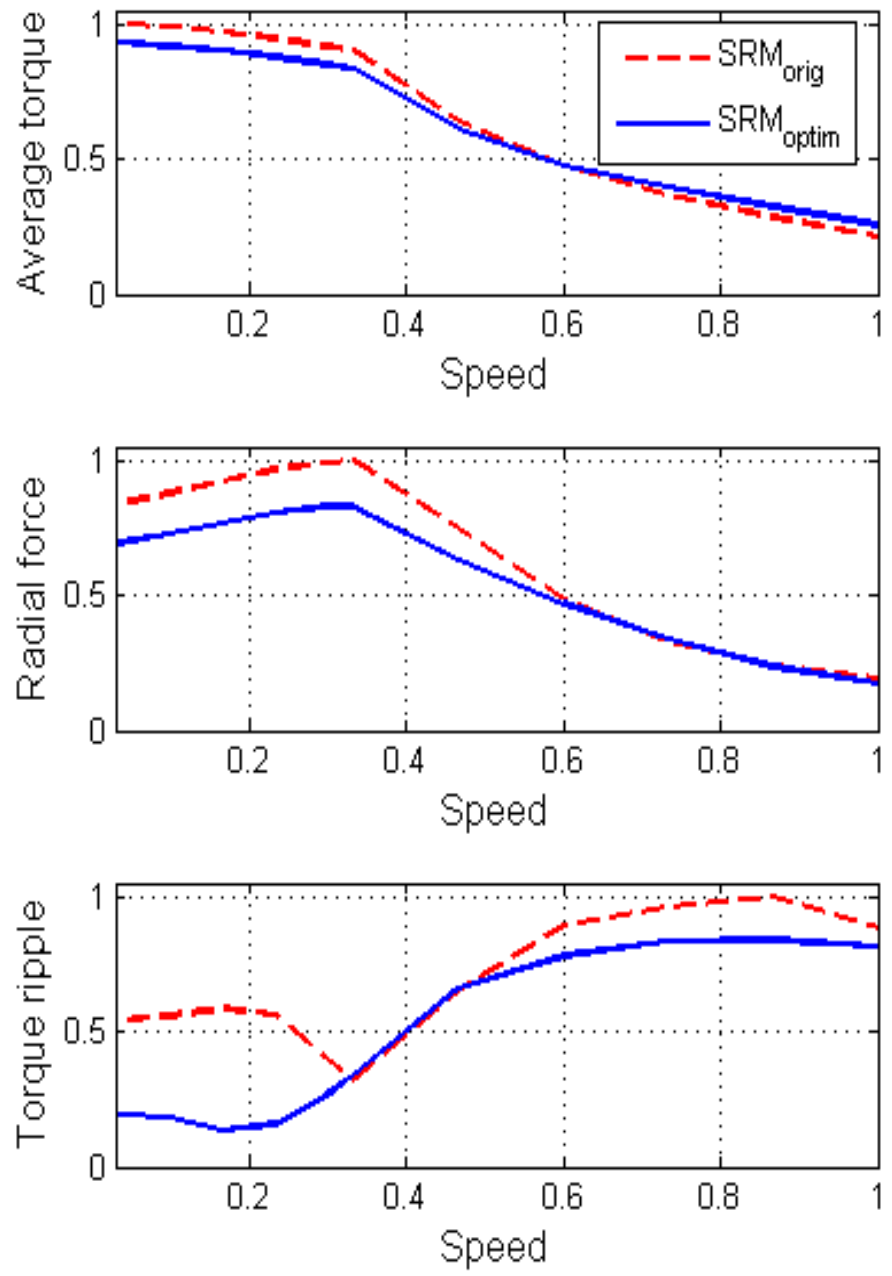

Fig. 7 (a) torque speed curves, (b) radial force as a function of speed, (c) torque ripples as a function of speed 


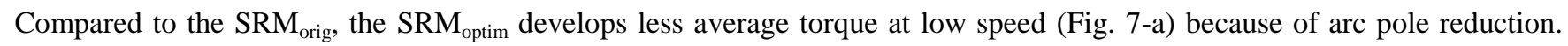
For the medium speeds, the optimized machine can reach the same torque as well as the original one. Furthermore, the optimized SRM can develop a higher average torque at high speeds. These last results are due to the low EMF (electromotive force) in the $\mathrm{SRM}_{\mathrm{optim}}$ related to the reduction of flux linkage (arc poles reductions). In addition, the $\mathrm{SRM}_{\mathrm{optim}}$ allows radial force reduction (Fig. 7-b) at low speed because of the reduction of the application surface of this force and flux linkage. At high speeds, the effect of the reduction of this surface is compensated by the increase in supply current due to the low EMF, and the optimized machine presents a radial force equivalent to the one of the $\mathrm{SRM}_{\text {orig. Targeting }} \mathrm{h}_{\mathrm{c} 1}$ in optimization leads to the decrease of the torque ripples in the majority of speeds, in particular at low speeds where the mechanical filtration is not effective (Fig. 7-c).

As the first harmonic reductions of radial force and torque were targeted by the optimization, figure "Fig. 8” illustrates their evolution according to the motor speed.
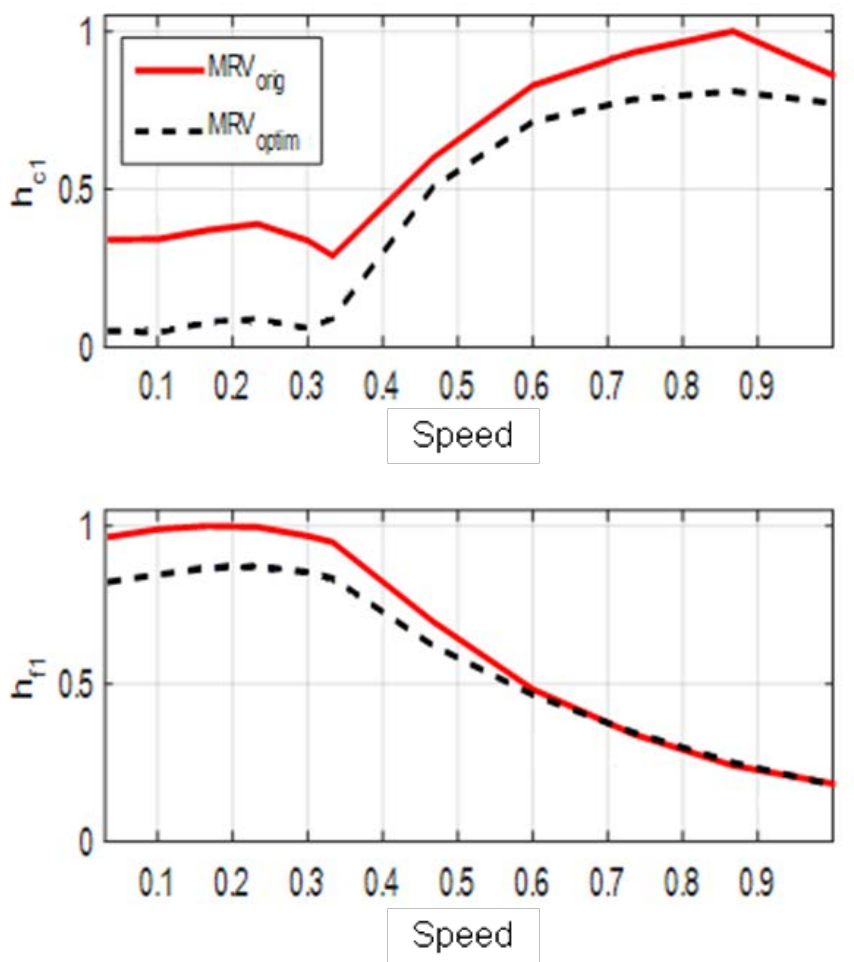

Fig. 8 Harmonics as function of the motor speed, (a) $h_{c 1}$, (b) $h_{f 1}$

Compared with $\mathrm{SRM}_{\text {orig, }}$, the optimized SRM reduces the first harmonic of the torque $\left(\mathrm{h}_{\mathrm{c} 1}\right)$ for the entire speed range and particularly at low speeds. As for the torque, the optimized machine reduces the first harmonic of radial force for $60 \%$ of speed range especially at low speeds. For the remaining $40 \%$ operating points (high speed), $\mathrm{h}_{\mathrm{f} 1}$ of $\mathrm{SRM}_{\text {optim }}$ is equivalent to the one

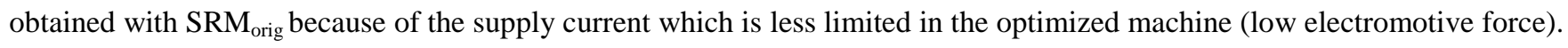




\section{4. $\quad$ Minimum torque ripples map}

Given the positive results above, the $\mathrm{SRM}_{\text {optim }}$ analysis is performed for the entire range of operation. Thus, the minimum torque ripples map of this machine is calculated and then compared to the $\mathrm{SRM}_{\text {orig }}$ one. These maps are computed with a research of the optimal control parameters (the reference current $\mathrm{I}_{\text {ref }}$, the conduction angle $\theta$ and the firing angle $\psi$ ) minimizing the torque ripples for each operating point [27]. Fig. 9 shows the maps associated to the two SRM in Fig. 9-a, Fig. 9-b and the difference between them expressed with $\delta$ (equation (2)) in Fig. 9-c.

$$
\delta=\frac{\Delta C_{\text {optim }}-\Delta C_{\text {orig }}}{\Delta C_{\text {orig }}}
$$

and

$$
\begin{aligned}
& \Delta \mathrm{C}_{\text {orig }}=\mathrm{C}_{\text {max }_{\text {orig }}}-\mathrm{C}_{\text {mim }} \text { orig } \\
& \Delta \mathrm{C}_{\text {optim }}=\mathrm{C}_{\text {max }_{\text {optim }}}-\mathrm{C}_{\text {mim optim }}
\end{aligned}
$$

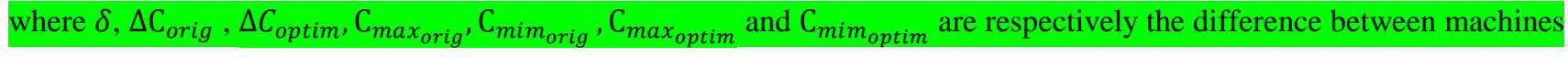
ripples, the $\mathrm{SRM}_{\text {orig }}$ ripples, the $\mathrm{SRM}_{\text {optim }}$ ripples, the maximum torque of $\mathrm{SRM}_{\text {orig }}$, the minimum torque of $\mathrm{SRM}_{\text {orig, }}$, the maximum torque of $\mathrm{SRM}_{\text {optim }}$ and the minimum torque of $\mathrm{SRM}_{\text {optim. }}$. 

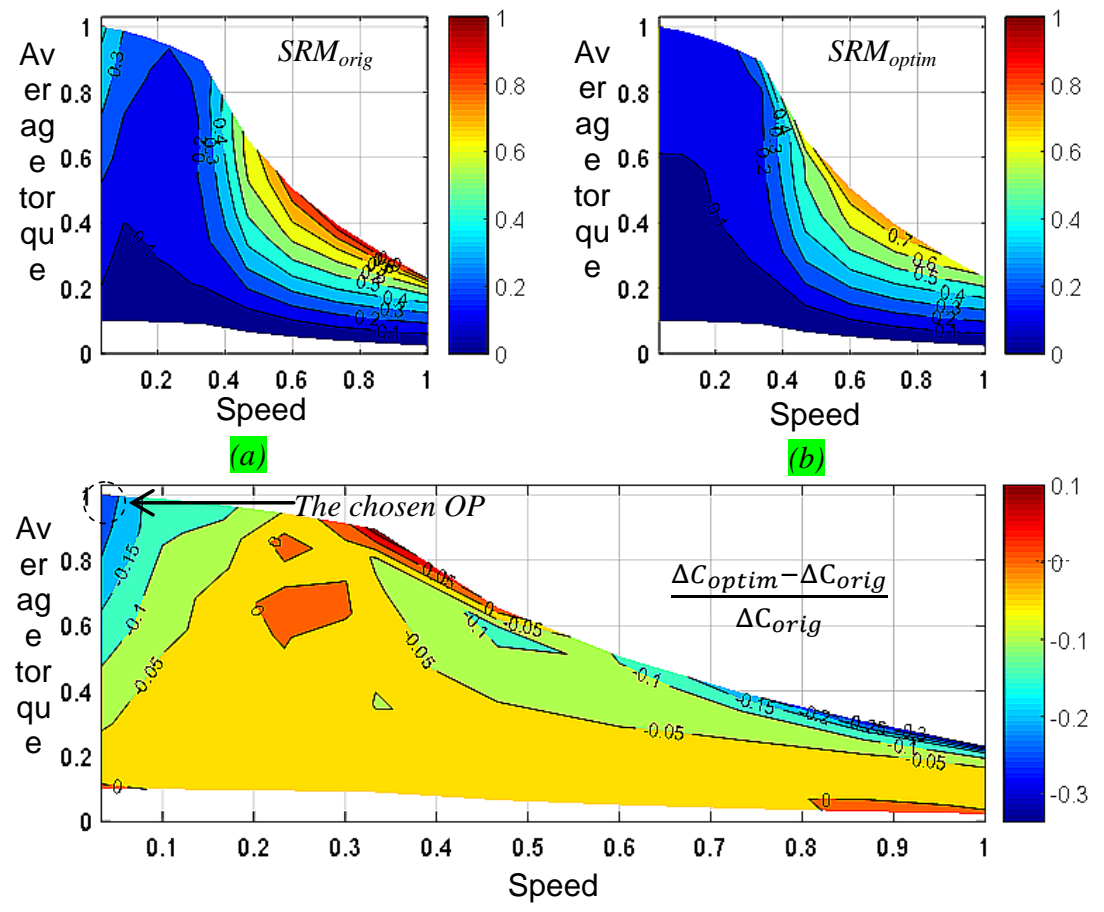

(c)

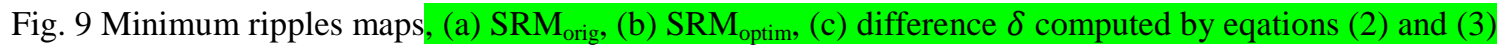

Torque ripples have similar evolutions for both motors. Torques have more important ripples at high average torque values where the choice of control parameters is limited $\left(I_{\text {ref }}=I_{\max }, \theta=180^{\circ}\right)$. With the comparison of the two machines, it is clear that the ripples of $\mathrm{SRM}_{\text {optim }}$ are lower compared to $\mathrm{SRM}_{\text {orig }}$ due to the minimization of the first torque harmonic in the optimization process (Fig 3-c): there are lower ripples in the $\mathrm{SRM}_{\text {optim }}$ for $90 \%$ of the operating points. The difference is on average $17 \%$ and can reach $27 \%$.

Fig. 10 shows the radial forces maps where the instantaneous radial force is computed for each operating point with the consideration of the control parameters obtained in the last section (minimum torque ripples maps). The figure 10-a presents the

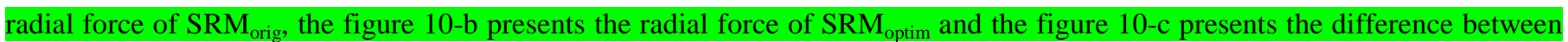
the two results, computed by equation (5).

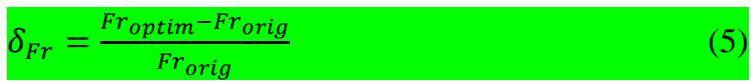

where $\delta_{F r}, F r_{\text {orig }}$ and $F r_{\text {optim }}$ are respectively the difference between machines radial forces, the SRM $\mathrm{orig}_{\text {rig }}$ radial force, the

$\mathrm{SRM}_{\text {optim }}$ radial force. 


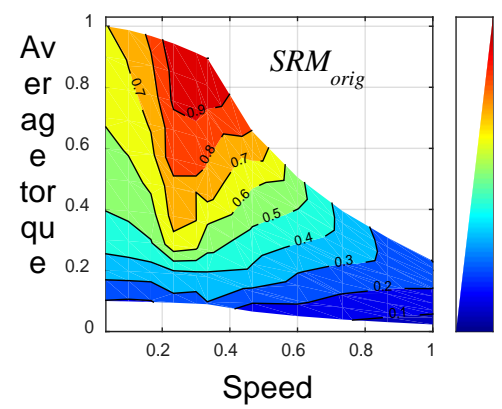

(a)
Av

er

ag

tor

qu

Speed

(b)
Av
er
ag
e
tor
qu

Speed

(c)

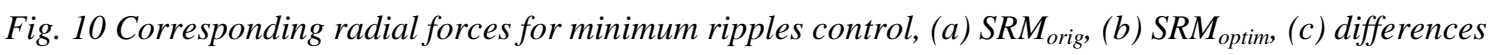

Radial forces of the two SRM have the same evolution: for a constant speed, the more the torque increases, the more the radial force increases also. Concerning the difference between the two machines, there are lower radial forces in the optimized structure, due to the minimization of the first harmonic of this radial force in the geometrical optimization. Indeed, the SRM $\mathrm{sptim}$ radial force is lower in $61 \%$ of the considered operating points and the difference can reach $32 \%$.

Among of the operating points which have smaller torque ripples (fig 9-c), 50\% of them have also less important radial force

(fig. 10-c). Those points are illustrated by red circles in the figure 11. In other words, for one of those operating points, we have looked for control parameters which allow smallest torque ripples for both machines (fig 9). In this case, the optimized SRM has the smallest ripple. So, with the same control parameters, we have computed the radial force for both machines at this point. It has been noticed that the optimal structure has also the less important radial force. So, in this operating point the optimized SRM presents the two advantages. 


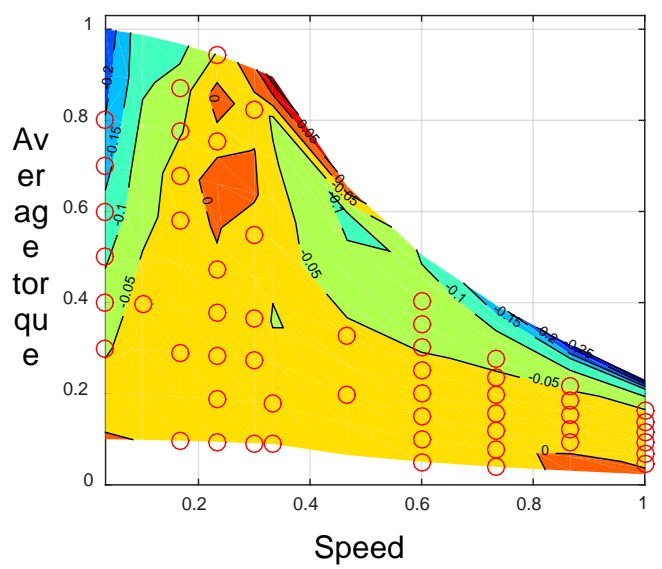

Fig. 11 Difference between torques ripples maps with the operating points which have less torque ripples and less radial force than $S R M_{\text {orig }}$

\section{CONCLUSION}

The structure of doubly saliency switched reluctance motor has been optimized on operating point for an automotive application. In this context, an original optimization process has been implemented to avoid two imbricated optimization loops which make the calculation time reasonable. In this process, the genetic algorithm was well associated with finite element analysis to reduce the radial force and the torque ripples without much affecting of the average torque. So, the optimized structure was then verified for all operating range. Although some drop in average torque, the optimized machine allowed the minimization of radial efforts and torque ripples. This result is due to the targeting of the first radial force harmonic and the first torque harmonic in the optimization. Thus, the electric vehicle user's comfort will improved.

\section{REFERENCES}

[1] I. Husain, "Minimization of torque ripple in SRM drives," Ind. Electron. IEEE Trans. On, vol. 49, no. 1, pp. $28-39,2002$.

[2] D. E. Cameron, J. H. Lang, and S. D. Umans, "The origin and reduction of acoustic noise in doubly salient variable-reluctance motors," IEEE Trans. Ind. Appl., vol. 28, no. 6, pp. 1250-1255, Nov. 1992.

[3] C. Pollock and C. Y. Wu, “Acoustic noise cancellation techniques for switched reluctance drives,” in Industry Applications Conference, 1995. Thirtieth IAS Annual Meeting, IAS’95., Conference Record of the 1995 IEEE, 1995, vol. 1, pp. 448-455.

[4] A. Yoshida, D. Tanaka, and I. Miki, “A study on the reduction of vibration and acoustic noise for switched reluctance motor," in Electrical Machines and Systems, 2005. ICEMS 2005. Proceedings of the Eighth International Conference on, 2005, vol. 1, pp. 520523.

[5] A. Kolli, G. Krebs, X. Mininger, and C. Marchand, "Impact of command parameters on efficiency, torque ripple and vibrations for Switched Reluctance motor,” in 2012 XXth International Conference on Electrical Machines (ICEM), 2012, pp. 2975-2980.

[6] A. Hofmann, A. Al-Dajani, M. Bosing, and R. W. De Doncker, "Direct instantaneous force control: A method to eliminate mode-0borne noise in switched reluctance machines,” in Electric Machines Drives Conference (IEMDC), 2013 IEEE International, 2013, pp. 1009-1016.

[7] B. Fahimi, G. Suresh, K. M. Rahman, and M. Ehsani, "Mitigation of acoustic noise and vibration in switched reluctance motor drive using neural network based current profiling," in Industry Applications Conference, 1998. Thirty-Third IAS Annual Meeting. The 1998 IEEE, 1998, vol. 1, pp. 715-722.

[8] R. Suryadevara and B. G. Fernandes, "Control techniques for torque ripple minimization in switched reluctance motor: An overview," 2013, pp. 24-29. 
[9] J.-P. Lecointe, Etude et réduction active du bruit d’origine magnétique des machines à réluctance variable à double saillance. Artois, 2003.

[10] X. Mininger, "Réduction des vibrations des machines à réluctance variable à l'aide d'actionneurs piézoélectriques,” THESE, École normale supérieure de Cachan - ENS Cachan, 2005.

[11] Y. Tang, "Switched reluctance motor with damping windings," US6008561 A, 28-Dec-1999.

[12] M. Besbes, C. Picod, F. Camus, and M. Gabsi, "Influence of stator geometry upon vibratory behaviour and electromagnetic performances of switched reluctance motors,” Electr. Power Appl. IEE Proc. -, vol. 145, no. 5, pp. 462 -468, Sep. 1998.

[13] J.-P. Hong, K.-H. Ha, and J. Lee, "Stator pole and yoke design for vibration reduction of switched reluctance motor," IEEE Trans. Magn., vol. 38, no. 2, pp. 929-932, Mar. 2002.

[14] S. P. Randall, “Noise reduction in reluctance machines,” US6072260 A, 06-Jun-2000.

[15] S. Ayari, "Etude des vibrations des machines à reluctance variable: influence des caractéristiques géométriques et de l'excentricité rotorique,” Ecole Normale Superieure de Cachan, France, 2000.

[16] M. N. Anwar and I. Husain, "Design perspectives of a low acoustic noise switched reluctance machine,” in Industry Applications Conference, 2000. Conference Record of the 2000 IEEE, 2000, vol. 1, pp. 99-106.

[17] P. O. Rasmussen, J. H. Andreasen, and E. C. LaBrush, "Interlaminated damping-a method for reduction of vibration and acoustic noise for switched reluctance machines?,” in Industry Applications Conference, 2005. Fourtieth IAS Annual Meeting. Conference Record of the 2005, 2005, vol. 3, pp. 1531-1539.

[18] M. Balaji and V. Kamaraj, "Design optimization of Switched Reluctance Machine using Particle Swarm Optimization,” in Electrical Energy Systems (ICEES), 2011 1st International Conference on, 2011, pp. 164-169.

[19] R. T. Naayagi and V. Kamaraj, "Modeling and design of shape optimized SRM with reduced ripple,” in Emerging Technologies, 2005. Proceedings of the IEEE Symposium on, 2005, pp. 399-404.

[20] J. Hur, G. H. Kang, J. Y. Lee, J. P. Hong, and B. K. Lee, "Design and optimization of high torque, low ripple switched reluctance motor with flux barrier for direct drive,” in Industry Applications Conference, 2004. 39th IAS Annual Meeting. Conference Record of the 2004 IEEE, 2004, vol. 1.

[21] Y. K. Choi, H. S. Yoon, and C. S. Koh, "Pole-shape optimization of a switched-reluctance motor for torque ripple reduction,” Magn. IEEE Trans. On, vol. 43, no. 4, pp. 1797-1800, 2007.

[22] P. C. Desai, M. Krishnamurthy, N. Schofield, and A. Emadi, "Novel Switched Reluctance Machine Configuration With Higher Number of Rotor Poles Than Stator Poles: Concept to Implementation,” IEEE Trans. Ind. Electron., vol. 57, no. 2, pp. 649 -659, Feb. 2010.

[23] Matlab MathWorks, “Optimization Software - Optimization Toolbox.” [Online]. Available: https://uk.mathworks.com/products/optimization/index.html. [Accessed: 05-Oct-2016].

[24] D. Meeker, “Finite Element Method Magnetics (Version 4.2), User’s Manual.” Oct-2010.

[25] M. Belhadi, "Étude de machines à réluctance variable pour une application de traction électrique : réduction des ondulations de couple et des efforts radiaux,” 2015.

[26] M. Besbes and B. Multon, "MRVSim code : Logiciel de simulation pour l'aide au dimensionnement des MRVDS et de convertisseur," IDDN.FR.001.430010.000.S.C.2004.000.30645, 2004.

[27] M. Belhadi, G. Krebs, C. Marchand, H. Hannoun, and X. Mininger, "Switched reluctance motor with magnetic slot wedges for automotive traction application,” Eur. Phys. J. Appl. Phys., vol. 72, no. 3, p. 30901, Dec. 2015. 